\title{
The Vollum Institute
}

\author{
Richard Sessions, Administrative Director
}

This year the Vollum Institute at Oregon Health Sciences University celebrates a decade of pathbreaking biomedical research. Today it carries forth the vision expressed at the time of its founding by then-university president Leonard Laster, who saw the Institute as a catalyst for university-wide development and for "attracting new staff in the vanguard of scientific discovery."

Sitting on top of Marquam Hill and overlooking the Willamette River, the city of Portland, and the mountains beyond, the Vollum began auspiciously. The nine-story, terra cottafaced building (Fig. 1)was designed by Robert Frasca of Zimmer-Gunsul-Frasca as "a place of the measurable, which is a laboratory, and a place of the unmeasurable" - a place where ideas are generated. The 67,000 square foot structure was completed in 1987. The following year it received the Laboratory of the Year award from Research $\theta$ Development magazine.

An endowment of $\$ 20$ million from Howard Vollum, cofounder of Tektronix, Inc., and his wife Jean, along with a federal construction grant of $\$ 20$ million obtained through the efforts of U.S. Senator Mark Hatfield made the institute possible. The M. J. Murdock Charitable Trust provided funds for equipping laboratories and recruiting the initial faculty.

The founding director of the Institute, Edward Herbert, was appointed in 1983. He focused the Institute's research on the molecular biology and cellular physiology of the brain, particularly the effects of hormones and genes on the nervous and endocrine systems, and on behavior. Herbert's laboratory discovered that the pituitary peptide adrenocorticotrophic hormone (ACTH) was synthesized as a polyprotein precursor, proopiomelanocortin (POMC). The polyprotein model of hormone biosynthesis developed by

Address correspondence and reprint requests to: Dr. Richard Sessions, Administrative Director, Vollum Institute L474, Oregon Health Sciences University, 3181 S.W. Sam Jackson Park Road, Portland, OR 97201-3098, U.S.A. Phone: 503-494-5042; Fax: 503-494-4590; E-mail: sessions@ohsu.edu

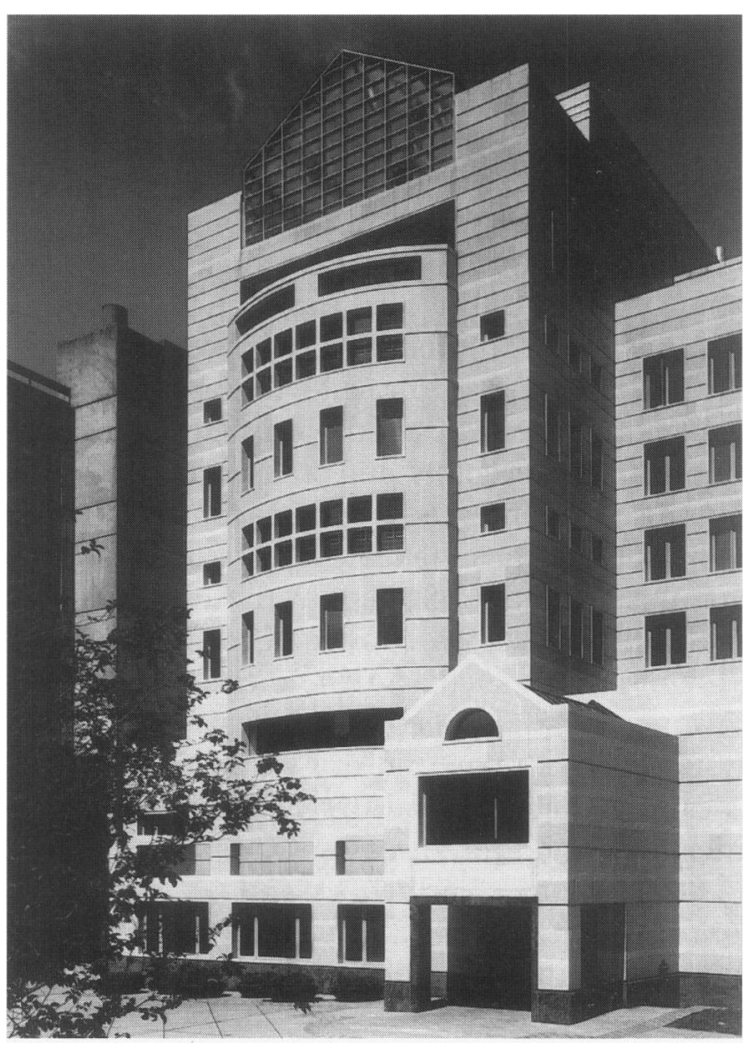

FIG. 1. The Vollum Institute

Herbert and colleagues provided a foundation for the emerging field of molecular endocrinology. Dr. Herbert recruited a handful of outstanding scientists to the Vollum, but unfortunately, he died just before the Institute's official opening. Several of his postdoctoral fellows became Institute faculty members and developed independent research programs.

From 1986 to 1990 the Institute gained a reputation for leading electrophysiological research on synaptic function and molecular biological research on new peptides and receptors. During 1988-91, the dopamine neurotransmitter receptor family was cloned at the Institute, which was an important breakthrough for neuroscientists and pharmacologists. Pharmaceutical 
companies were keenly interested in the dopamine D4 receptor for the development of better drugs for schizophrenia. Research on new treatments for other diseases affected by the dopamine system, such as Parkinson's disease, was also expanded by the advance.

In 1989, OHSU President Peter Kohler recruited another molecular neuroendocrinologist, Richard H. Goodman, from the Tufts-New England Medical Center to be the new director of the Vollum. Goodman brought four other members of his division who also became faculty members of the Institute. By the end of 1991, the institute faculty had increased to nineteen, and NIH grant awards had nearly doubled to $\$ 5.7$ million annually. Goodman expanded the research themes of the Institute to include studies of signal transduction in tissues beyond the brain. The research interests of faculty now included gene regulation, characterization of hormone and neurotransmitter receptors and transporters, elucidation of second messenger systems, protein kinases and protein phosphatases, and studies of ion channel regulation. Studies at the Institute hold implications for a wide range of brain and endocrine disorders, such as Alzheimer's disease, Parkinson's disease, epilepsy, schizophrenia, mood dysfunction, stroke, and drug addiction, as well as cancer, diabetes, and thyroid, kidney, gastrointestinal, and viral diseases.

The Vollum's early work and several significant research findings in the next few years gave the Vollum an international reputation as a leading neuroscience institute. Two investigators isolated, expressed, and characterized a family of voltage-gated potassium channels-membrane proteins that have important functions for the excitable properties of neurons and muscles. Two other investigators made seminal contributions to knowledge of the functions of the major excitatory CNS neurotransmitter glutamate, and its receptors. Excitatory synapses provide mechanisms for learning and memory, and when disrupted, can contribute to neuropsychiatric diseases such as epilepsy and stroke. In a discovery that may ultimately result in new treatments for cocaine addiction, one investigator cloned and expressed the dopamine transporter molecule, a key site of cocaine's action. Another investigator and a colleague in the biochemistry department discovered that an amino acid transporter is commandeered as a receptor by a leukemia-producing retrovirus. This opened a new research area on transporter function. The receptors for the peptide hormones melanocyte-stimulating hormone (MSH) and ACTH were isotlated at another laboratory in the Institute. This research offered the promise of new understanding of brain pathways for the peptides and could contribute to new clinical advances for melanoma, pigmentation disorders, and other diseases. Unexpectedly, these findings provided new insights into the pathophysiology of obesity.

The Vollum's investigators have received such accolades such as the Society of Neuroscience New Investigator Award, the George $\mathrm{H}$. Hitchings Award for Innovative Methods in Drug Discovery and Design, and the John Jacob Abel Award in Pharmacology. In addition, the Institute has developed several campus-wide programs: three NIH training grants and three program project grants involve Vollum investigators. A neuroscience graduate program founded during the Institute's early years was expanded to include faculty from the OHSU departments of Cell and Developmental Biology, Physiology and Pharmacology, Biochemistry, Neurology, Behavioral Neuroscience, Medical Genetics, and the Center for Research on Environmental Toxicology. Other institutions participating in the program are the nearby VA Medical Center, the R. S. Dow Neurological Sciences Institute in downtown Portland, and the Oregon Regional Primate Research Center in Beaverton. In part because of the Vollum's presence, the university has attracted additional leading scientists to basic science and clinical departments, and the volume of OHSU extramural grant awards has increased severalfold.

Much of the Vollum's success derives from the faculty's highly interactive way of working together. The open-lab style of architecture and the informal culture that naturally developed both support a strong sense of community. Vollum investigators contribute to each other's grant proposals and royalty earnings are allocated to the graduate programs, benefiting all laboratories. The institute has brought about a productive marriage of physiological, genetic, molecular biological, and behavioral techniques which are reported in multi-author publications published in the leading scientific journals. Recent discoveries appearing in these journals include: new attributes of the glutamate transporters; identification and characterization of highaffinity antagonists of the central melanocortin receptors in the brain and elucidation of the key role that the MC3 and MC4 receptors play in weight homeostasis; delineation of the molecular mechanisms of pain; characterization of the piv- 
otal function of the protein CaM-kinase II for triggering cellular learning and memory; examination of how key enzymes in a cell are tethered to certain locations by anchoring proteins; and the discovery of the CREB binding protein (CBP) and its central role as a transcriptional integrator.

Although Institute research focuses on neuroscience, approximately half of the faculty have non-neuroscience backgrounds. Vollum faculty all receive joint appointments in School of Medicine departments and frequently participate in the teaching of graduate students, even though faculty are not required to do so. Vollum appointments and promotions are based on a contract system. Assistant Scientists (equivalent to Assistant Professors) are reviewed after five years. For promotion to Scientist, they must be recognized nationally as significant contributors in their fields. Similarly, Scientists are appointed for five years and must be seen as nationally recognized leaders in their fields to be promoted to Senior Scientist. Senior Scientists are reviewed every five years. The Vollum Scientific Advisory Committee, composed of outstanding researchers from other institutions, meets yearly and participates in the review process. A unique feature of Vollum review criteria is that the amount of grant support is not considered in promotional reviews. The philosophy is that a person doing great science will be able to get grant support, but the reverse is not necessarily true.
Now in its tenth year, the Vollum Institute can gauge its success in many ways. Two of its twenty faculty have been appointed Howard Hughes Medical Institute investigators. Its sponsored research funding has reached \$11 million, and its endowment has doubled. The Institute's technologies have been licensed by numerous pharmaceutical and biotechnology companies, bringing in the lion's share of OHSU's licensing and royalty income, and two Portland-based biotechnology companies originated from Vollum technology. In September 1997 the Vollum marked a decade of progress by hosting an international symposium, "Neuronal Signaling: Cell Membrane to Nucleus," featuring the world's leading researchers in signal transduction. More than 400 scientists, fellows, and students attended this symposium.

As a showcase of OHSU's potential, the Vollum Institute continues to set new standards and to make fundamental biological discoveries in the effort to cure brain-related diseases. The faculty, trainees, and support staff look forward to the second decade with tremendous optimism.

\section{ACKNOWLEDGMENTS}

I thank Eve Goodman for her editorial assistance. 